\title{
Risk factors, symptoms and effects of urinary schistosomiasis on anthropometric indices of school children in Zaria, Kaduna state, Nigeria
}

\begin{abstract}
Nigerian children suffer a great burden of parasitic infections. Urinary schistosomiasis is associated with children's daily indulgence in uncontrolled water activities in unsafe water bodies. The study was aimed at assessing the level of urinary schistosomiasis among school children in Zaria-Nigeria, as well as the risk factors, signs/symptoms and effects associated with it. A total of 200 children from different primary schools in Zaria consented to this study through their parents and school managements. Urine sample $(10 \mathrm{mls})$ and anthropometric indices (weight in kilogram, height in meters, mid-arm circumference in centimeters) were obtained from each pupil, followed by administration of a structured questionnaire. The samples were analysed at the Department of Veterinary Parasitology and Entomology, Ahmadu Bello University Zaria. The overall prevalence of urinary schistosomiasis among the pupils was $21(10.5 \%)$. The male pupils $16(14.8 \%)$ were significantly more infected than the female pupils 5(5.4\%). Also children within the age of 13-14years and 9-10years had the most infections. Swimming and irrigation farming were found to be significant risk factors $(\mathrm{P} \leq 0.05)$. The infection was significantly associated with abdominal pain, painful urination, and frequent urination and visible haematuria. Pupils with mid-arm circumference of $21.0-22.9 \mathrm{~cm}$ had the highest infections but there was not significant association with the disease. Pupils with normal BMI had more infections than the underweight pupils but the relationship was statistically insignificant. This study did not find harmful associations between urinary schistosomiasis and anthropometric indices considered. There is an urgent need of efforts to control schistosomiasis in Nigeria.
\end{abstract}

Keywords: urinary schistosomiasis, zaria, school children, effects, anthropometric index, risks, symptoms
Volume 2 Issue I - 2018

Henry Gabriel Bishop, Ruth lye Akoh

Department of Microbiology, Ahmadu Bello University, Nigeria

Correspondence: Henry Gabriel Bishop, Department of Microbiology, Faculty of Life Sciences, Ahmadu Bello University, Zaria, Nigeria, Tel +2 348I 76357626 Email gabrielhenrybishop@gmail.com

Received: October 20, 2017| Published: February 02, 2018
Abbreviations: BMI, body mass index; CM, centimeter; $\chi^{2}$, chi square; KG, kilogram; M, meter; MAC, mid-arm circumference; MLS, milliliters; NTDS, neglected tropical diseases; OR, odd ratio; RPM, revolutions per minute; SPSS, statistical package for social sciences; UNICEF, united nations international children's emergency fund; US CIA, united states central intelligence agency; WHA, world health organization

\section{Introduction}

In Nigeria, children of ages $0-14$ years make $43.01 \%$ of its population structure (US CIA World Fact book, 2016; The Carter Center. ${ }^{1}$ The nation suffers from many neglected tropical diseases (NTDs) with a great deal of schistosomiasis cases. School children are vulnerable to schistosomiasis, which has remained a major public health problem in Nigeria. ${ }^{2}$ The disease is one of the world's oldest diseases, ${ }^{3}$ yet not many countries have eliminated it. However, countries like Japan and Egypt have eradicated schistosomiasis, though about 230-240 million individuals worldwide are infected, thereby helping in the spread of the disease. ${ }^{4-6}$ Nigeria is one of the African countries endemic for the disease (GSA) with a prevalence of $9.5 \% .{ }^{7}$ A prevalence of $12.3 \%$ had been reported by ${ }^{8}$ with an emphasis on unawareness of the disease among children as the cause of its continued spread. So many complications can arise due to underlying Schistosoma infection: bladder cancer Infections Landscapes, ${ }^{9}$ anemia, ${ }^{9}$ funiculitis, painful urination, prostatitis, laziness, fistulization and haemospermia WHO. Less attention has been given towards control of the disease in Nigeria, hence it menace is increasing. Poverty, abundant snail population, unsafe water sources, and uncontrolled juvenile watercontact activities are among the frequently reported risk factors. ${ }^{10-13}$ This research was aimed at finding the prevalence, risk factors, signs/symptoms, and effects of urinary schistosomiasis on children's anthropometric indices in Zaria, Nigeria.

\section{Materials and methods}

\section{Study area and consent}

The study was conducted in Zaria, Kaduna State, Nigeria. The pupils, their parents and teachers were briefed on the importance of the study and ethical consents were obtained. For the benefit of the study, each pupil was given his/her test result. Those that had Schistosoma haematobium infections were referred to the hospital for medical attention.

\section{Collection of samples}

Urine samples $(10 \mathrm{mls}$ each) were collected from consented pupils. Structure questionnaires were administered to gather data on demography, risk factors and signs/symptoms of schistosomiasis from the children. The samples were covered in dark cold containers and 
conveyed for analysis at the Department of Veterinary Parasitology and Entomology, Ahmadu Bello University, Zaria.

\section{Anthropometric indices}

For each pupil, the weight in kilogram $(\mathrm{kg})$, height in meters $(\mathrm{m})$ and mid-arm circumference in centimeters $(\mathrm{cm})$ were measured with a weighing scale, a calibrated meter rule, and a flexible tape respectively. The body mass index (BMI) was determined by dividing the weight by square of the height. BMI was compared with the standard by Health Promotion Degree. ${ }^{14}$ The MAC was compared with the standard of the WHO/UNICEF. ${ }^{12}$ However, since the entire subjects had MAC of greater $12.5 \mathrm{~cm}$, the data were further categorized into six groups varying by an interval of 2 for analysis.

\section{Laboratory analyses}

Each urine sample was examined for visible color and transferred into a labelled centrifuge tube. Centrifugation was done at $3000 \mathrm{rpm}$ for 5 minutes. The supernatant was discarded and the sediments were collected using Pasteur pipettes. Wet mount of the sediments was made with addition of Lugol's iodine to enhance contrast and cover slip was placed. Microscopy was done using the light microscope at 10x and 40x objectives. Color atlases were used to aid identification of Schistosoma haematobium ova. Any sample with Schistosoma haematobium count of $\geq 50$ egg per $10 \mathrm{ml}$ urine was considered as heavy infection; otherwise it was light infection.

\section{Statistical analyses}

Laboratory results and data collected from questionnaires were subjected to statistical analyses (Chi Square, $\chi^{2}$ and Odd ratio, OR) at $=0.05$ using the IBM SPSS version 21 .

\section{Results}

Out of 200 school children in primary school involved in this study between the ages of 5-14years, 92 were females while 108 were males. Overall prevalence of urinary schistosomiasis was 21(10.5\%) (Figure 1). Light infection cases were $20(10.0 \%)$ while only one case of heavy infection found in a male (Figure 2). The male pupils $16(14.8 \%)$ were significantly more infected than $5(5.4 \%)$ female pupils $\left(\chi^{2}=4.651\right.$, $\mathrm{df}=1, \mathrm{P}=0.031, \mathrm{OR}=3.026$ ). Pupils within the age of $7-8$ years had more infections followed by those of 13-14 years, but there was no infection in pupils of 5-6 and 9-10years $\left(\chi^{2}=11.144, \mathrm{df}=4, \mathrm{P}, 0.025\right)$ (Table 1). Among the risk factors considered, swimming $\left(\chi^{2}=6.102\right.$, $\mathrm{df}=1, \mathrm{P}=0.014, \mathrm{OR}=3.578)$ and irrigation farming $\left(\chi^{2} 5.541, \mathrm{df}=1\right.$, $\mathrm{P}=0.019, \mathrm{OR}=3.368$ ) had significant associations with occurrence of urinary schistosomiasis. Pupils that involved in fishing activity were 2.105times more at risk of getting the infection than those who did not. Considering the source of domestic water, pupils that used wells were most infected with Schistosoma haematobium than those that either use boreholes or taps (Table 2).

Abdominal pain $(\chi 2=24.682, \mathrm{df}=1, \mathrm{P}=0.000, \mathrm{OR}=8.763)$, painful urination $\left(\chi^{2}=17.747, \mathrm{df}=1, \mathrm{P}=0.000, \mathrm{OR}=6.455\right)$, red-colored urine $\left(\chi^{2}=10.732, \mathrm{df}=1, \mathrm{P}=0.005\right)$ and frequent urination $\left(\chi^{2}=4.480, \mathrm{df}=1\right.$, $\mathrm{P}=0.034, \mathrm{OR}=2.628$ ) were found to be significant signs/symptoms of schistosomiasis (Table 3). The anthropometric indices examined showed that pupils with the lowest and highest MAC had no infection compared to other categories but the relationship was insignificant. Also, pupils with normal BMI were rather more infected with Schistosoma haematobium than those that were underweight (Table 4).

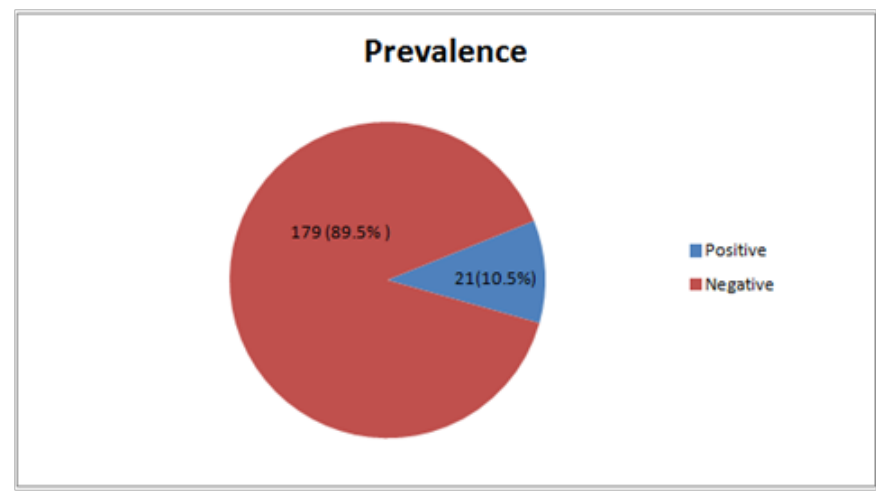

Figure I Overall prevalence of urinary schistosomiasis among school children in Zaria, Nigeria.

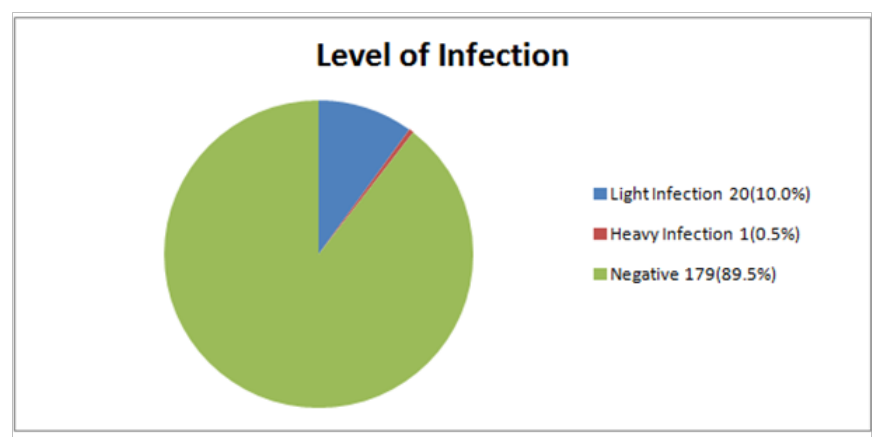

Figure 2 Level of urinary schistosomiasis among school children in Zaria, Nigeria.

Table I Occurrence of urinary schistosomiasis by demographic factors of school children in Zaria

\begin{tabular}{lll}
\hline Parameter & Number examined & Number positive (\%) \\
\hline Gender* & 92 & $5(5.4)$ \\
Female & 108 & $16(14.8)$ \\
Male & 200 & $21(10.5)$ \\
Total & & \\
Age** (Years) & 4 & $0(0.0)$ \\
6-May & 17 & $4(23.5)$ \\
8-Jul & 30 & $0(0.0)$ \\
I0-Sep & 48 & $2(4.2)$ \\
I2-Nov & 101 & I5(I4.9) \\
I3-I4 & 200 & $21(10.5)$ \\
Total & &
\end{tabular}

Table 2 Risk factors associated with urinary schistosomiasis among school children in Zaria, Nigeria

\begin{tabular}{lll}
\hline Risk factor & Number examined & Number positive (\%) \\
\hline Swimming & & \\
No & 176 & $15(8.5)$ \\
Yes & 24 & $6(25.0)$ \\
\hline
\end{tabular}


Table Continued..

\begin{tabular}{|c|c|c|c|}
\hline Risk factor & Number examined & \multicolumn{2}{|c|}{ Number positive (\%) } \\
\hline \multicolumn{4}{|c|}{ Irrigation farming } \\
\hline No & 175 & $15(8.6)$ & \\
\hline Yes & 25 & $6(24.0)$ & \\
\hline \multicolumn{4}{|l|}{ Fishing ${ }^{c}$} \\
\hline No & 178 & $17(9.6)$ & \\
\hline Yes & 22 & $4(18.2)$ & \\
\hline \multicolumn{4}{|c|}{ Water Source $^{d}$} \\
\hline Borehole & 144 & $13(9.0)$ & \\
\hline Tap & 31 & $3(9.7)$ & \\
\hline Well & 25 & $5(20.0)$ & \\
\hline \multicolumn{2}{|c|}{$\begin{array}{l}\mathrm{a} \chi^{2}=6.102, d f=I, P=0.014, O R=3.578 \\
O R=3.368\end{array}$} & $d f=I$, & $P=0.019$, \\
\hline \multicolumn{4}{|c|}{${ }^{c} \chi^{2}=1.552, d f=I, P=0.213, O R=2.10 ; \quad{ }^{d} \chi^{2}=2.755, d f=2, P=0.252$} \\
\hline
\end{tabular}

Table 3 Signs/Symptoms of urinary schistosomiasis among pupils in Zaria, Nigeria

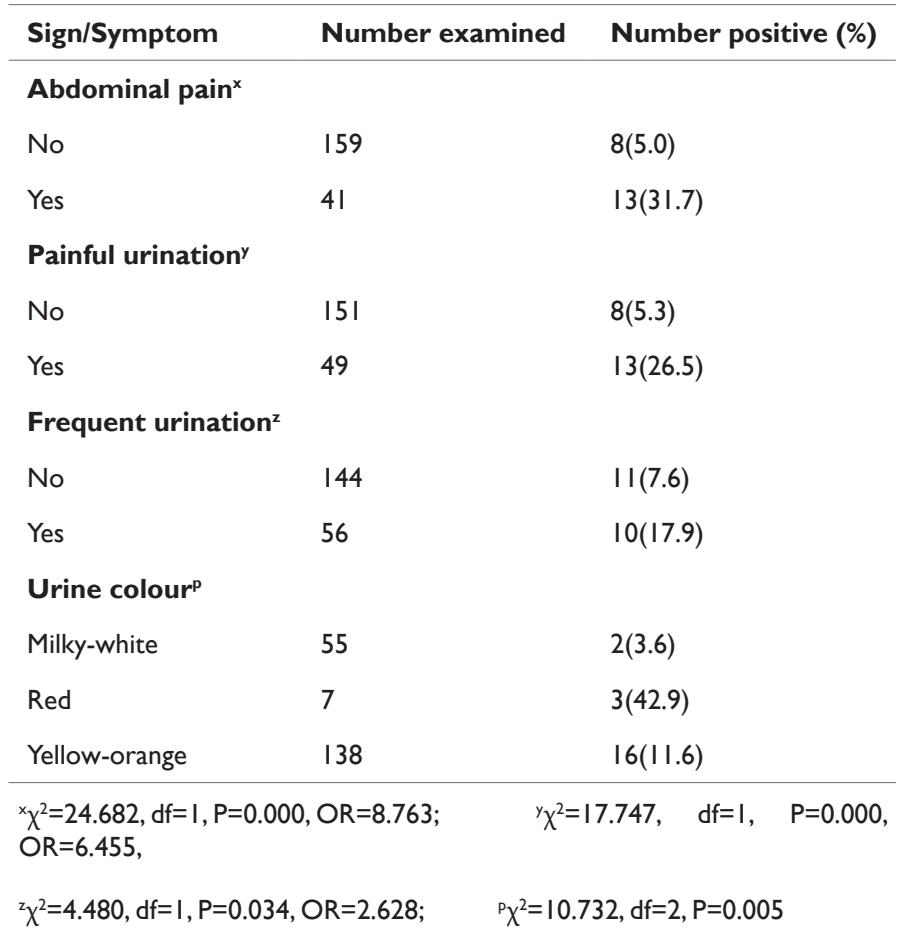

Table 4 Effects of urinary schistosomiasis on some anthropometric indices of pupils in Zaria, Nigeria

\begin{tabular}{lll}
\hline Anthropometric index & $\begin{array}{l}\text { Number } \\
\text { examined }\end{array}$ & Number positive (\%) \\
\hline MAC category* $(\mathrm{Cm})$ & & \\
$15.0-16.9$ & 21 & $0(0.0)$ \\
$17.0-18.9$ & 62 & $8(12.9)$ \\
$19.0-20.9$ & 59 & $5(8.5)$ \\
\hline
\end{tabular}

Table Continued.

\begin{tabular}{lll}
\hline Anthropometric index & $\begin{array}{l}\text { Number } \\
\text { examined }\end{array}$ & Number positive (\%) \\
\hline MAC category* $(\mathrm{Cm})$ & & $7(14.9)$ \\
$21.0-22.9$ & 47 & $\mathrm{I}(\mathrm{II} .1)$ \\
$23.0-24.9$ & 9 & $0(0.0)$ \\
$\geq 25$ & 2 & \\
Body mass index** & & $7(10.9)$ \\
Normal & 64 & $14(\mathrm{I} 0.3)$ \\
Underweight & 136 & \\
\hline${ }^{*} \chi^{2}=4.306, \mathrm{df}=5, \mathrm{P}=0.506 ;$ & $* \chi^{2}=0.019, \mathrm{df}=\mathrm{I}, \mathrm{P}=0.890, \mathrm{OR}=0.934$ \\
Discussion & &
\end{tabular}

Urinary schistosomiasis is still a neglected health burden among children in Nigeria. The prevalence of $10.5 \%$ found in this study indicated a rise from the reported prevalence of $9.5 \%$ by the Nigerian Federal Ministry of Health in 2015. ${ }^{7}$ However, prevalence report from this study was lower than $12.3 \%$ reported by. Some locations in Nigeria are highly endemic for urinary schistosomiasis with prevalence of about $50-80 \% ;^{15-19}$ a few other locations have $0-10 \%$ of the population infected. ${ }^{20-22}$ The high number of light infection cases that occurred among the children was an indication of low intensity of the disease in the region. Heavy infections can only result from repeated exposures to schistosome cercariae in infested water. ${ }^{23}$ The prevailing disease situation is an indication that the efforts aimed at eliminating some NTDs by health-promotion agencies need serious intensification. Many researches had implicated male children with higher risk of schistosomiasis as found in this study. Only very few researches had reported a higher occurrence in female children. ${ }^{18}$ The male children probably had more infections because they have higher tendencies of indulging in open water-activities like swimming, fishing and wadding than the girls. ${ }^{24,25}$ reported similar gender distribution.

Children of 5-6years of age were not infected probably because they are too small to engage in water activities in unsafe water bodies like the other children of higher age-groups. This agreed with the findings. Also, ${ }^{26}$ observed that schistosomiasis decreases with increase in age. Older children often indiscriminately indulge in open water activities than adults. Swimming and irrigation farming were found to associate with the occurrence of the disease in the study population. More commonly, reported risk factors of schistosomiasis always include unawareness, swimming, irrigation farming, fishing, wadding, use of water from rivers or dams. ${ }^{27,28}$ Schistosomes can penetrate intact skin during contact with cercarial-infested water bodies. ${ }^{25}$ Also, children that engaged in fishing activities as well as those that use wells as main source of water had more infections because of the high tendencies of coming in contact with cercariae from infested water. Some wells maybe poorly managed and exposed to snail infestation.

In this study, abdominal pain, passing out red-colored urine accompanied by pain and high frequency were the signs/symptoms that associated with the disease. The presence of red-colored urine indicated haematuria. This agreed with many other reports. ${ }^{29-32}$ Schistosoma haematobium infection can discomfort a child's daily school activities due to the pain and/or high urge for urination. No significant association was found between urinary schistosomiasis and BMI or MAC in this study. All the children had MAC greater than 
$12.5 \mathrm{~cm}$ as compared with the WHO/UNICEF standard for detection of malnutrition. However, schistosomiasis can affect the health condition of children; especially in the form of growth stunting and poor academic performance in school. ${ }^{21-23}$ Some will miss school in the course of diagnosis and treatment.

\section{Conclusion}

The prevalence of urinary schistosomiasis among school children in Zaria, Nigeria was found to be $10.5 \%$. There was $10.0 \%$ cases of light infections and only $0.05 \%$ of heavy infection. The male children are 3.026 times at higher risk of getting the infection than the females. Swimming and irrigation farming were found to be associated risk factors of urinary schistosomiasis. Most of the infected children significantly had abdominal pain and painful urination at high frequency; their urine samples were red in color indicating the presence of haematuria. There was no significant indication of any effects of urinary schistosomiasis on both the body mass index and mid-arm circumference of the children. All the children had MAC above $12.5 \mathrm{~cm}$. However, children in Zaria still suffer from urinary schistosomiasis. The solution, therefore, is routine surveys and interventions. The parents and school teachers should help at ensuring that pupils do not indulge in any activities in or at near unprotected water bodies through proper awareness and caution. Government, WHO, UNICEF and other charity organizations should intensify efforts on provision of safe water to communities in Nigeria as well enlightenment programs on the disease.

\section{Acknowledgements}

We sincerely acknowledge the help rendered us during this study by the staff of Helminthology Laboratory, Department of Veterinary Parasitology and Entomology, Ahmadu Bello University Zaria.

\section{Conflict of interest}

The authors declare that there is no any financial interest or any conflict of interest in this work.

\section{References}

1. US Central Intelligence Agency (CIA). The world Fact Book, Nigeria; 2016.

2. Johannesburg Summit. Nigeria: country profile. Chapter 6: Protecting and promoting human health. CP2002-Nigeria. 2002. p. 15-16.

3. Olajide AO, Olajide FO, Aremu AA, et al. Ureteric obstruction secondary to schistosomiasis 2 years after Praziquantel therapy: a case report. The Pan African Medical Journal. 2012;12:32.

4. Barsoum RS, Esmat G, El Baz T. Human Schistosomiasis: clinical perspective: review. Journal of Advanced Research. 2013;4(5):433-444.

5. Gomes LI, Enk MJ, Rabello A. Diagnosis of Schistosomiasis. Where are we? Revista da Sociedade Brasileira de Medicina Tropical. 2014:47(1):3-11.

6. WHO. Genital manifestations of schistosomiasis. Nigeria; 2016.

7. Global Network. Government of Nigeria releases new data on the prevalence of schistosomiasis and intestinal worms, Nigeria; 2015.

8. Bishop HG, Inabo HI, Ella EE. Prevalence and intensity of urinary schistosomiasis and their effects on packed cell volume of pupils in Jaba LGA, Nigeria. Edorium Journal of Microbiology. 2016;2:13-26

9. Elbaz T, Esmat G. Hepatic and intestinal schistosomiasis: review. Journal of Advanced Research. 2013;4(5):445-452.
10. Ekpo UF, Laja Deile A, Oluwole AS, et al. Urinary schistosomiasis among preschool children in a rural community near Abeokuta, Nigeria. Parasite \& Vector. 2010;3:1-58.

11. WHO. Schistosomiasis: number of people treated worldwide in 2013. Weekly Epidemiological Record. 2015;5(90):25-32.

12. WHO/UNICEF. Mid-upper arm cirucumference (MUAC) measuring tape. $2009 ; 13(2): 1-2$.

13. The Carter Center. Waging peace, fighting disease. Building hopeNigeria. 2016.

14. Health Promotion Degree. Body mass index (BMI) and pregnancy. Nigeria; 2012.

15. Bala AY, Ladan MU, Mainasara M. Prevalence and intensity of urinary Schistosomiasis in Abarma village, Gusau, Nigeria: a preliminary investigation. Science World Journal. 2012;7(2):1-4

16. Bigwan EI, Kunihya RZ, John TJ. Epidemiological survey of urinary Schistosomiasis among primary school children in Michika, Adamawa State, North-Eastern Nigeria. International Journal of Current Research and Review. 2013;5(5):111-116.

17. Uneke C, Egede M. Impact of urinary schistosomiasis on nutritional status of school children in South-Eastern Nigeria. The Internet Journal of Health. 2008;9(1):1-7.

18. Oluwasogo OA, Fagbemi OB. Prevalence and risk factors of Schistosoma haematobium infections among primary school children in Igbokuta Village, Ikorodu North Local Government, Lagos State. IOSR Journal of Nursing and Health Science. 2013;2(6):62-68.

19. Hassan AO, Amoo AOJ, Akinwale OP, et al. Current status of urinary schistosomiasis in communities around the Erinle and Eko-Ende Dams and the implications for schistosomiasis control in Nigeria. South African Journal of Infectious Diseases. 2014;29(4):137-140.

20. Ingang Etoh PC, Essien UC, Amama SA, et al. Prevalence of urinary schistosomiasis among school children in Ukwelo-Obudu and Abini communities in Cross River State, Nigeria. Port Harcourt Medical Journal. 2009;3(3):1-4.

21. Uneke C, Ugwuoke Adibuah S, Nwakpu K, et al. An Assessment of Schistosoma haematobium infection and urinary tract bacterial infection among school children in rural eastern Nigeria. The Internet Journal of Laboratory Medicine. 2009;4(1):1-6.

22. Dawaki S, Al Mekhlafi HM, Ithoi I, et al. The menace of schistosomiasis in Nigeria: knowledge, attitude, and practices regarding schistosomiasis among rural communities in Kano State. PLOS ONE. 2015;10(11):e0143667.

23. Sakanari JA, Mckerrow JH. Medical Parasitology. In: GF Brooks, KC Carroll et al. editors. Medical Microbiology. 25th edn. McGraw Hill Companies, USA; 2010. p. 665-701.

24. Ossai OP, Dankoli R, Nwodo C, et al. Bacteruria and urinary schistosomiasis in primary school children in rural communities in Enugu State, Nigeria, 2012. Pan Afr Med J. 2014;18(1 supple 15):1-5.

25. Omenesa HO, Bishop HG, Raji HM. Prevalence of urinary schistosomiasis among pupils attending primary schools in Bomo Village, Zaria-Nigeria. International Journal of Research in Engineering and Science. 2015;3(5):14-19.

26. Kanwai S, Ndams IS, Kogi E, et al. Urinary schistosomiasis infection in Dumbin Dustse, Igabi Local Government Area, Kaduna State, Nigeria. Science World Journal. 2011;6(3):1-3.

27. Brindley PJ, Hotez PJ. Break out: urogenital schistosomiasis and Schistosoma haematobium infection in the post-genomic era. P PLoS. Negl Trop Dis. 2013;7(3):1961. 
28. Mohager MO, Mohager SO, Kaddam LA. The association between schistosomiasis and enteric fever in a single Schistosoma endemic area in Sudan. International Journal of Pharmaceutical Sciences and Research. 2014;5(6):2181-2184.

29. Cheesbrough M. District Laboratory Practice in Tropical Countries, Part I. 2nd ed. updated. Cambridge University Press, Cambridge, UK; 2009. p. 1-442.

30. King $\mathrm{CH}$. Schistosomiasis: challenges and opportunities. In: Institute of Medicine (US) Forum on Microbial Threats. The Causes and Impacts of Neglected Tropical and Zoonotic Diseases: Opportunities for Integrated Intervention Strategies. Washington (DC): National Academies Press, USA; 2011.
31. Infection Landscapes. Schistosomiasis. 2012.

32. World Health Organization. Report of the WHO informal consultation on schistosomiasis control. Geneva, Switzerland; 1999. p. 49 